\title{
How will sea level respond to changes in natural and anthropogenic forcings by 2100 ?
}

\author{
S. Jevrejeva, ${ }^{1}$ J. C. Moore, ${ }^{2}$ and A. Grinsted ${ }^{3}$ \\ Received 17 February 2010; revised 2 March 2010; accepted 5 March 2010; published 3 April 2010.
}

[1] Using an inverse statistical model we examine potential response in sea level to the changes in natural and anthropogenic forcings by 2100 . With six IPCC radiative forcing scenarios we estimate sea level rise of $0.6-1.6 \mathrm{~m}$, with confidence limits of $0.59 \mathrm{~m}$ and $1.8 \mathrm{~m}$. Projected impacts of solar and volcanic radiative forcings account only for, at maximum, $5 \%$ of total sea level rise, with anthropogenic greenhouse gasses being the dominant forcing. As alternatives to the IPCC projections, even the most intense century of volcanic forcing from the past 1000 years would result in $10-15 \mathrm{~cm}$ potential reduction of sea level rise. Stratospheric injections of $\mathrm{SO}_{2}$ equivalent to a Pinatubo eruption every 4 years would effectively just delay sea level rise by 12-20 years. A 21 st century with the lowest level of solar irradiance over the last 9300 years results in negligible difference to sea level rise. Citation: Jevrejeva, S., J. C. Moore, and A. Grinsted (2010), How will sea level respond to changes in natural and anthropogenic forcings by 2100?, Geophys. Res. Lett., 37, L07703, doi:10.1029/2010GL042947.

\section{Motivation}

[2] For the past 150 years sea level rise has been associated with rapid increase in anthropogenic factors of climate forcing [Jevrejeva et al., 2009]. Only $4 \mathrm{~cm}(25 \%$ of total sea level rise) during the 20th century can be attributed to natural (volcanic and solar irradiance) forcing, the remaining $14 \mathrm{~cm}$ are due to rapid increase in carbon dioxide $\left(\mathrm{CO}_{2}\right)$ and other greenhouse gases [Jevrejeva et al., 2009]. The Fourth Assessment Report of the Intergovernmental Panel on Climate Change (IPCC) suggested $18-59 \mathrm{~cm}$ sea level rise by 2100 with an additional $10-20 \mathrm{~cm}$ on the upper limit associated with rapid dynamical changes in ice flow of the ice sheets [Meehl et al., 2007]. Lately these IPCC numbers have been challenged with new estimates of 0.5-1.4 $\mathrm{m}$ [Rahmstorf, 2007], 0.75-1.90 m [Vermeer and Rahmstorf, 2010], 0.8$2.0 \mathrm{~m}$ [Pfeffer et al., 2008] and 0.8-1.3 m [Grinsted et al., 2010] sea level rise by 2100 .

[3] The approach used by IPCC to estimate future sea level rise has been to model the major components of sea level budget: ocean thermal expansion and ice melting. However, the observational sea level budget is not yet closed [Bindoff et al., 2007]; in addition, there is some controversy about the relative importance of individual contri-

\footnotetext{
${ }^{1}$ Proudman Oceanographic Laboratory, Liverpool, UK.

${ }^{2}$ College of Global Change and Earth System Science, Beijing Normal University, Beijing, China.

${ }^{3}$ Centre for Ice and Climate, Niels Bohr Institute, University of Copenhagen, Copenhagen, Denmark.
}

Copyright 2010 by the American Geophysical Union. 0094-8276/10/2010GL042947 bution from the ice sheets and glaciers melting and changes in ocean heat content [Bindoff et al., 2007; Jevrejeva et al., 2008] and uncertainties associated with ice sheet mass balance [Meehl et al., 2007]. An alternative approach to climate model simulations for assessing sea level rise and forecasting future changes are statistical models, which are based on physically plausible semi-empirical relationships between past or predicted future global temperature changes and sea level rise [Rahmstorf, 2007; Grinsted et al., 2010; Vermeer and Rahmstorf, 2010]. The observationally tuned statistical methods give significantly higher estimates of sea level rise those than used in previous IPCC reports.

[4] In this study, instead of projecting individual components of sea level rise separately, we estimate global sea level rise in the 21 st century using a statistical model driven by total natural and anthropogenic forcings. We consider sea level as an integrated response of the entire climate system (including feedback processes) to the changes in radiative forcing that reflects changes in the dynamics and thermodynamics of the atmosphere, ocean and cryosphere. Thus mean global sea level is an independent measurement of global response than mean global temperature, which has typically been the target series of both attribution studies [e.g., Hegerl et al., 2007; Meehl et al., 2007] and future modeling scenarios [Meehl et al., 2007]. In this study we focused only on the response of sea level to the changes in volcanic, solar, greenhouses gases and aerosols climatic forcings. We do not consider any changes in sea level associated with non-climate related components such as contribution from groundwater mining, urbanization and sequestration of water in reservoirs. Lettenmaier and Milly [2009] suggest, on the basis of observations, that land, overall, contributes essentially nothing to sea-level rise today.

[5] Here we address two main questions. First, how will global sea level respond to the expected changes in radiative forcing over the next 100 years? Second, what is the relative importance of natural and anthropogenic forcings in 21 st century sea level rise?

\section{Description of the Forcings}

\subsection{IPCC Radiative Forcing Projections}

[6] We have utilized the central estimates of radiative forcing projections from six Special Report on Emission Scenarios (SRES) scenarios: A1B, A1Fi, A1T, A2, B1, B2 [Meehl et al., 2007], which combine anthropogenic and natural forcings. Anthropogenic forcing projections vary widely due to wide variations in emissions forecasts for radiative gas species $\left(\mathrm{CO}_{2}, \mathrm{CH}_{4}\right.$ and $\left.\mathrm{SO}_{2}\right)$. Other unknowns include gas species interactions [Shindell et al., 2009] and uncertainty on feedback responses and climate sensitivity. 


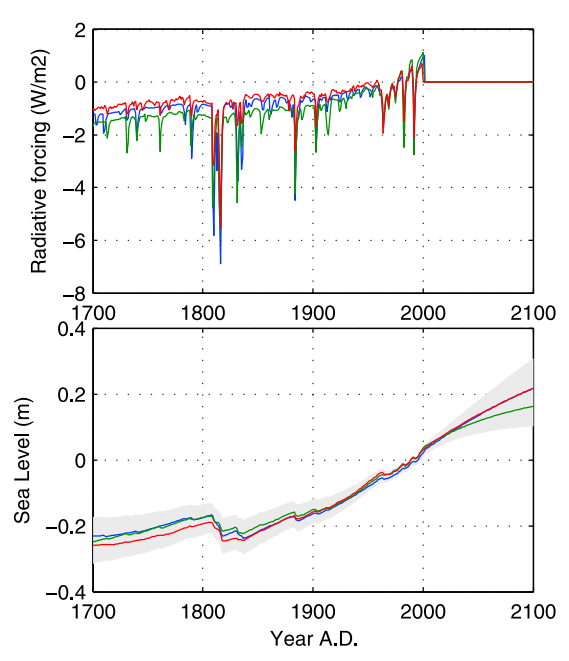

Figure 1. (top) Radiative forcings until 2000 from three independent sources: blue - Crowley et al. [2003]; green Goosse et al. [2005]; red - Tett et al. [2007]; since 2001 "no changes in radiative forcing". (bottom) Projections of sea level rise up to 2100 with "no changes in radiative forcing" since 2000. Colors the same as in Figure 1 (top), light grey shadow -5 and $95 \%$ limits.

Anthropogenic factors dominate radiative forcing for the 21 st century in all 6 IPCC scenarios [Meehl et al., 2007].

\subsection{IPCC $\mathrm{CO}_{2}$ Only Forcing}

[7] To estimate sea level response to the radiative forcing from $\mathrm{CO}_{2}$ alone we have used projected $\mathrm{CO}_{2}$ concentrations (central values) from IPCC scenarios: $\mathrm{A} 1 \mathrm{Fi}, \mathrm{B} 2$ and A1T [Meehl et al., 2007], and A1B, B1 and A2 available from http://data.giss.nasa.gov/modelforce/ghgases/. Radiative forcings due to changes in $\mathrm{CO}_{2}$ concentration are then computed using the near log-linear relationship described by Hansen et al. [1998]. In this a doubling of $\mathrm{CO}_{2}$ concentration over pre-industrial corresponds to $4.1 \mathrm{~W} / \mathrm{m}^{2}$. Uncertaintity in climate sensitivity will propagate as errors in our sea level projections, however, we use several different radiative forcing reconstructions to provide a probabilistic set of sea level scenarios.

\subsection{Natural (Solar and Volcanic) Forcings}

[8] Estimates of future natural forcings in IPCC reports are limited. We therefore created our own scenario for the 21 st century based on the most extreme century of volcanic radiative forcing over the last 1000 years (the 13th century) [Crowley et al., 2003; Goosse et al., 2005]. In addition we synthesized a 21 st century with a geoengineering-like stratospheric $\mathrm{SO}_{2}$ injection equivalent to the $1991 \mathrm{Mt}$. Pinatubo eruption occurring every 4 years, and a reduced value of solar constant set to the lowest value inferred to have occurred over the last 9300 years $\left(1364.64 \mathrm{~W} / \mathrm{m}^{2}\right)$ [Steinhilber et al., 2009].

\section{Model Description}

[9] We use our semi-empirical model [Grinsted et al., 2010; Jevrejeva et al., 2009], constrained by the global sea level record from tide gauges [Jevrejeva et al., 2008], and driven by various forcing time series. We assume that for a given mean global radiative forcing $(F)$ there is an equilibrium sea level $\left(S_{e q}\right)$. As we described previously [Grinsted et al., 2010; Jevrejeva et al., 2009] the relationship between $S_{e q}$ and $F$ must be non-linear for large changes in sea level such as those that occur on glacial-interglacial timescales, however, we can do a linearization that is valid for Late Holocene climate:

$$
S_{e q}=a F+b
$$

where $a$ is the sensitivity of sea level to a forcing $(F)$ change and $b$ is a constant.

[10] We consider that sea level rise is the result of changes in global ice volume and global ocean heat content, both of which we model as reacting to changes in radiative forcing with some single response time of the climate system $(\tau)$. Naturally the global ocean heat content and ice volume will have different response times, however both are plausibly centennial [Grinsted et al., 2010]. We therefore assume that sea level will approach $S_{e q}$ as follows:

$$
\frac{\partial S}{\partial t}=\left(S_{e q}-S\right) / \tau
$$

We integrate equation (2) to give sea level $(S)$ over time using a history of $F$ and information of the initial sea level at the start of integration $\left(S_{0}\right)$. We use 2000000 member ensemble Monte Carlo inversion, calibrated by the 300 year tide gauge record, to determine the probability density functions of the unknown parameters $a, b, \tau, S_{0}$ [Grinsted et al., 2010].

[11] To calculate three different sets of model parameters $a, b, \tau, S_{0}$ we use reconstructions of forcings [Crowley et al., 2003; Goosse et al., 2005; Tett et al., 2007] for the past 1000 years (Table S1). ${ }^{1}$ These model parameters are then used on the future forcing factor scenarios discussed in section 2 to determine future sea level response.

[12] In our previous study we have showed that there is a reasonable agreement between three sea level reconstructions based on independent radiative forcings over the past 1000 years [Jevrejeva et al., 2009]. Sea level is almost identical for all three experiments since 1800 and in excellent agreement with available observations [Jevrejeva et al., 2008], providing support that this model can be used for the future 100 year sea level projections.

\section{Results}

\subsection{Experiment "No Changes in Radiative Forcing"}

[13] In this experiment we test the model response to "no changes in radiative forcing" where future radiative forcing is constant relative to the period 1980-2000. The model simulations (Figure 1) provide evidence that sea level would continue to rise up to $0.16-0.22 \mathrm{~m}$ (with 5-95\% confidence limits of $0.1 \mathrm{~m}$ and $0.3 \mathrm{~m}$ ) during the $21 \mathrm{st}$ century despite radiative forcing being unperturbed from present day values. This result demonstrates that there is substantial inertia in the climate-sea level system and conditions established during the past centuries have already committed the world to a sea level rise during the next 100 years that likely will exceed the rise experienced during the 20th century.

\footnotetext{
${ }^{1}$ Auxiliary materials are available in the HTML. doi:10.1029/ 2010 GL042947.
} 

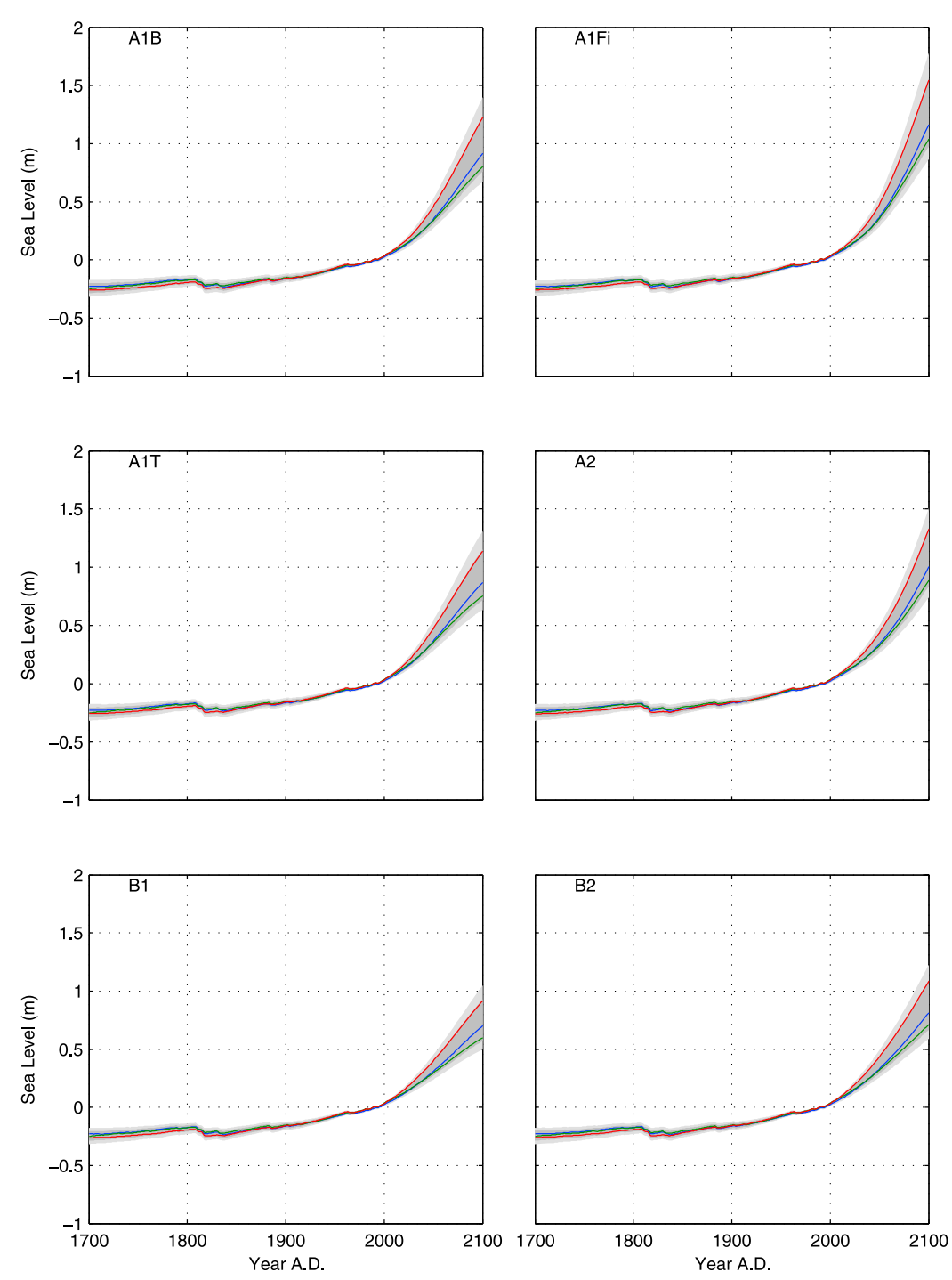

Figure 2. Projections of sea level rise during the 21 st century using six IPCC radiative forcing scenarios, numbers are given relative to the period 1980-2000. Colors represent model parameters calculated using past forcings, colors and shaded bands are as Figure 1.

\subsection{Sea Level Responses to Radiative forcing Changes Using IPCC Scenarios}

[14] Sea level responses to radiative forcing from six IPCC scenarios are presented in Figure 2 (and Table S2). There is a close agreement of the sea level rise until about 2050 , with a range of about $0.30-0.55 \mathrm{~m}$. By midcentury, the choice of scenario becomes more important for the magnitude of sea level rise. By the end of the century there are clear consequences depending on which scenario is followed, with a range of sea level rise from 0.6 to $1.6 \mathrm{~m}$ by 2100 due to distinct differences between the various radiative forcing scenarios.

[15] This estimated range of sea level rise is consistent with previous results of $0.5-1.4 \mathrm{~m}$ [Rahmstorf, 2007], 0.75$1.90 \mathrm{~m}$ [Vermeer and Rahmstorf, 2010] and 0.8-1.3 m [Grinsted et al., 2010] based on the projections of sea level with IPCC temperature increase scenarios. Our projected 0.6-1.6m sea level rise support indirect estimates [Rohling et al., 2008] of $1.6 \mathrm{~m}$ sea level rise per century under sustained temperatures $2^{\circ} \mathrm{C}$ degrees above present. If the latest
IPCC estimates of $0.1-0.41 \mathrm{~m}$ rise from thermal expansion of ocean water are correct, then the remaining rise we predict must come from ice sheets and glaciers, which is in good agreement with previous independent estimates $(0.49$ $1.7 \mathrm{~m}$ ) of potential contribution from Greenland/Antarctica ice sheets and small glaciers [Pfeffer et al., 2008].

\subsection{Response to Changes in $\mathrm{CO}_{2}$ Alone}

[16] The net radiative forcing of greenhouse gasses is almost the same as that due to $\mathrm{CO}_{2}$ alone through the 20th century since the radiative effects of other greenhouse gasses practically cancels that of anthropogenic aerosols. Hence sea level appears completely dominated by $\mathrm{CO}_{2}$ concentrations. The projections of aerosols and other greenhouse gases radiatiative effects through the 21 st century have much larger uncertainties than those of $\mathrm{CO}_{2}$ [Meehl et al., 2007], so the future sea level response to $\mathrm{CO}_{2}$ has an extra uncertainty in this regard.

[17] We also pushed the model by forcing with a $1200 \mathrm{ppm}$ $\mathrm{CO}_{2}$ concentration by 2100 - this has been modeled to produce $6.3^{\circ} \mathrm{C}$ warming by 2100 [Meehl et al., 2007]. This 


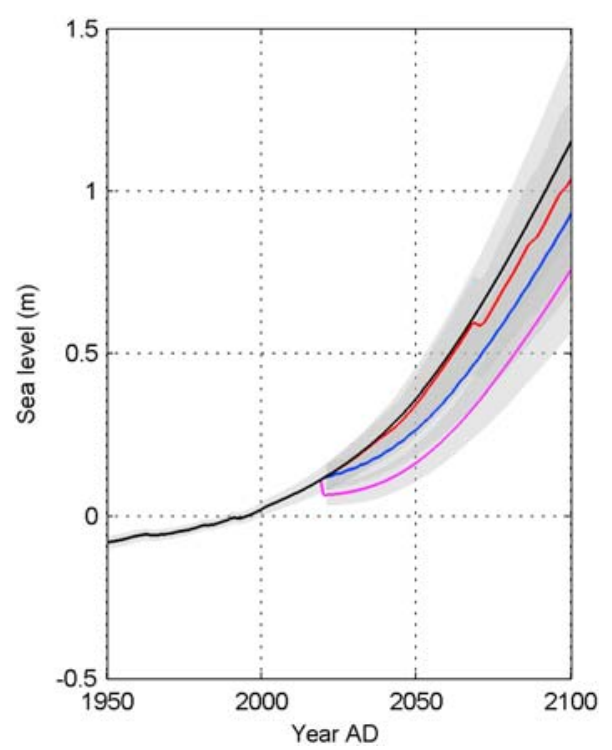

Figure 3. Sea level projection using model parameters based on fitting past sea level to forcings from Crowley et al. [2003] with A1Fi IPCC scenario (black solid line) since 2001; with A1Fi plus impacts from volcanic forcing scenarios "13th century" (red); with A1Fi and effect of a Pinatubo eruption every four year (blue) since 2020; with A1Fi and effect of Pinatubo eruption every two year (magenta) since 2020.

is about the same as the glacial-interglacial global temperature increase, so the likelihood of the semi-empirical model being unreliable is great. Nevertheless the predicted sea level response by 2100 is indistinguishable from the A1Fi scenario. Although the long term sea level rise would be tens of meters, the thermal inertia of the sea level-climate system has a centennial scale response time, which damps the rate of rise during the 21 st century.

\subsection{Potential Contribution From Natural Forcings}

[18] To estimate some possible contributions from natural forcings we have created several scenarios for future solar and volcanic forcings. Recent estimates of Total Solar Irradiance (TSI), [see Steinhilber et al., 2009, Table 1] all give between 0.9 and $1.3 \mathrm{~W} / \mathrm{m}^{2}$ differences between the Maunder Minimum and the mean of the solar cycle 22 (1986-1996). The Holocene minimum value of TSI is $1364.64 \mathrm{~W} / \mathrm{m}^{2}$ [Steinhilber et al., 2009], this corresponds to a drop of about $1 \mathrm{~W} / \mathrm{m}^{2}$ relative to the mean over the past 22 years and will result in $10-20 \mathrm{~cm}$ reduction in sea level by 2100 . This compares with our $0.6-1.6 \mathrm{~m}$ estimates of sea level rise due to anthropogenic forcing in the 21st century. Such a minor solar contribution is in good agreement with Benestad and Schmidt [2009] who conclude negligible solar forcing from 1980 to 2002 .

[19] Figure 3 demonstrates volcanic forcing of sea level rise. We show the A1Fi radiative forcing projection added to a "13th century" scenario of volcanic forcing, where the volcanic forcing has been taken from Crowley et al. [2003]. Here we selected the period 1190-1289, since it is one of the periods with particularly high level of volcanic activity, including the largest eruption of an unknown volcano in the last 7,000 years - the AD 1258 event. Sea level response to "13th century" volcanic forcing in the 21 st century would result in up to $8 \mathrm{~cm}$ lowering of sea level. Nevertheless, this reduction would be only $20 \%$ of sea level rise for a low emission scenarios such as B1; for the other scenarios, the contribution from "13th century" volcanic eruptions will counter less than $10 \%$ of sea level rise. A similar sea level response (not shown) would arise from selectively combining early 19th and late 20th century volcanic forcing which included the Tambora eruption in 1815, Agung in 1963, El Chichon in 1982 and Pinatubo in 1991.

[20] Figure 3 also shows the results of geoengineering the planet by stratospheric sulphate aerosol injection, taking the reduction of radiative forcing modelled by Robock et al. [2008] equivalent to a Pinatubo every 4 years. This scenario would reduce sea level rise by $22 \mathrm{~cm}$. Even with a Pinatubo every 2 years and the A1Fi emissions scenario, sea level rise would be $0.76 \mathrm{~m}$ by 2100 , with $5-95 \%$ confidence limits of $0.55 \mathrm{~m}$ and $0.95 \mathrm{~m}$.

[21] Detection and attribution studies indicate that volcanism was the most prominent forcing factor for climate variability of the last 1000 years [Hegerl et al., 2007]. However, in the 21 st century the contribution from volcanic forcing will be almost unnoticeable. To produce as significant an impact on 21 st century sea level rise as it accounted for the 20th century (30\% of all forcings), volcanic forcing must be continuously 10 times stronger than observed during the 20th century.

\section{Conclusion}

[22] With the assumption that sea level will continue to respond over the next 100 years to the same forcings that have influenced it during the past 1000 years, we estimate $0.6-1.6 \mathrm{~m}$ of global sea level rise in the 21 st century using a statistical model driven by projected natural and anthropogenic forcings. In contrast to the 20th century sea level rise that was associated with a significant contribution of $25 \%$ from natural (solar and volcanic) forcing, 21st century sea level rise will be clearly dominated by the changes in $\mathrm{CO}_{2}$ and other greenhouse gases.

[23] Alternative scenarios for solar forcing with a potential decrease in solar irradiance of $1 \mathrm{~W} / \mathrm{m}^{2}$ (using the lowest level recorded throughout the last 9300 years) only produce a $10-20 \mathrm{~cm}$ reduction in our estimate of 21st century sea level rise. If we utilize the 13th century past volcanic forcing to estimate a possible (but unlikely) contribution from volcanic activity, then an almost negligible $8 \mathrm{~cm}$ decrease is projected in the estimated sea level rise. The suggested reduction of radiative forcing by injections of $\mathrm{SO}_{2}$ into atmosphere (equivalent to a Pinatubo eruption every 4 years) would be equivalent to delaying sea level rise by $12-20$ years.

[24] A "no changes in radiative forcing" scenario produced 16-22 cm (with lower limit of $10 \mathrm{~cm}$ and upper limit of $31 \mathrm{~cm}$ ) sea level rise in the 21 century due to the inertia of the climate system, providing evidence that conditions established during the past centuries have already committed us to a considerable global sea level rise during the next 100 years.

[25] Confidence in our sea level estimates comes from the similarity of sea level response to temperature forcing from independent models calibrated using different paleo sea level reconstructions [Vermeer and Rahmstorf, 2010; 
Rahmstorf, 2007]. Since our results are based on observed past relationships between forcing and sea level, future ice and ocean responses to 21 st century climate change may be systematically in error.

[26] Acknowledgment. We are grateful to the anonymous reviewers for constructive criticisms which helped to improve an earlier draft of this manuscript.

\section{References}

Benestad, R. E., and G. A. Schmidt (2009), Solar trends and global warming, J. Geophys. Res., 114, D14101, doi:10.1029/2008JD011639.

Bindoff, N. L., et al. (2007), Observations: Oceanic climate change and sea level, in Climate Change 2007: Contribution of Working Group I to the Fourth Assessment Report of the IPCC, edited by S. Solomon et al., pp. 385-432, Cambridge Univ. Press, New York.

Crowley, T. J., S. K. Baum, K.-Y. Kim, G. C. Hegerl, and W. T. Hyde (2003), Modeling ocean heat content changes during the last millennium, Geophys. Res. Lett., 30(18), 1932, doi:10.1029/2003GL017801.

Goosse, H., H. Renssen, A. Timmermann, and R. S. Bradley (2005), Internal and forced climate variability during the last millennium: a modeldata comparison using ensemble simulations, Quat. Sci. Rev., 24, 1345-1360, doi:10.1016/j.quascirev.2004.12.009.

Grinsted, A., J. C. Moore, and S. Jevrejeva (2010), Reconstructing sea level from paleo and projected temperatures 200 to 2100 AD, Clim. Dyn., 34, 461-472, doi:10.1007/s00382-008-0507-2.

Hansen, J., M. Sato, A. Lacis, R. Ruedy, I. Tegen, and E. Matthews (1998), Perspective: Climate forcings in the industrial era, Proc. Natl. Acad. Sci. U. S. A., 95, 12,753-12,758, doi:10.1073/pnas.95.22.12753.

Hegerl, G. C., T. J. Crowley, M. Allen, W. T. Hyde, H. N. Pollack, J. E. Smerdon, and E. Zorita (2007), Detection of human influence on a new, validated 1500-year temperature reconstruction, J. Clim., 20, 650-666, doi:10.1175/JCLI4011.1.

Jevrejeva, S., J. C. Moore, A. Grinsted and P. L. Woodworth (2008), Recent global sea level acceleration started over 200 years ago?, Geophys. Res. Lett., 35, L08715, doi:10.1029/2008GL033611.

Jevrejeva, S., J. C. Moore, and A. Grinsted (2008), Relative importance of mass and volume changes to global sea level rise, J. Geophys. Res., 113, D08105, doi:10.1029/2007JD009208.

Jevrejeva, S., A. Grinsted, and J. C. Moore (2009), Anthropogenic forcing dominates sea level rise since 1850, Geophys. Res. Lett., 36, L20706, doi:10.1029/2009GL040216.
Lean, J. L., and D. H. Rind (2008), How natural and anthropogenic influences alter global and regional surface temperatures: 1889 to 2006, Geophys. Res. Lett., 35, L18701, doi:10.1029/2008GL034864.

Lettenmaier, D. P., and P. C. D. Milly (2009), Land waters and sea level, Nat. Geosci., 2(7), 452-454, doi:10.1038/ngeo567.

Meehl, G. A., et al. (2007), Global climate projections, in Climate Change 2007: Contribution of Working Group I to the Fourth Assessment Report of the IPCC, edited by S. Solomon et al., pp. 747-846, Cambridge Univ. Press, New York.

Pfeffer, W. T., J. T. Harper, and S. O’Neel (2008), Kinematic constraints on glacier contributions to 21 st-century sea-level rise, Science, 321,1340 1343, doi:10.1126/science. 1159099 .

Rahmstorf, S. (2007), A semi-empirical approach to projecting future sealevel rise, Science, 315, 368-370, doi:10.1126/science.1135456.

Robock, A., L. Oman, and G. L. Stenchikov (2008), Regional climate responses to geoengineering with tropical and Arctic $\mathrm{SO}_{2}$ injections, J. Geophys. Res., 113, D16101, doi:10.1029/2008JD010050.

Rohling, E. J., K. Grant, C. Hemleben, M. Siddall, B. A. A. Hoogakker, M. Bolshaw, and M. Kucera (2008), High rates of sea-level rise during the last interglacial period, Nat. Geosci., 1, 38-42, doi:10.1038/ ngeo.2007.28.

Shindell, D. T., G. Faluvegi, D. M. Koch, G. A. Schmidt, N. Unger, and S. E. Bauer (2009), Improved attribution of climate forcing to emissions export, Science, 326, 716-718, doi:10.1126/science.1174760.

Steinhilber, F., J. Beer, and C. Fröhlich (2009), Total solar irradiance during the Holocene, Geophys. Res. Lett., 36, L19704, doi:10.1029/ 2009 GL040142.

Tett, S. F. B., R. Betts, T. J. Crowley, J. Gregory, T. C. Johns, A. Jones, T. J. Osborn, E. Ostrom, D. L. Roberts, and M. J. Woodage (2007), The impact of natural and anthropogenic forcings on climate and hydrology since 1550, Clim. Dyn., 28(1), 3-34, doi:10.1007/s00382-006-0165-1.

Vermeer, M., and S. Rahmstorf (2010), Global sea level linked to global temperature, Proc. Natl. Acad. Sci. U. S. A., doi:10.1073/pnas. 0907765106 , in press.

A. Grinsted, Centre for Ice and Climate, Niels Bohr Institute, University of Copenhagen, Juliane Mariesvej 30, Copenhagen DK-2100, Denmark.

S. Jevrejeva, Proudman Oceanographic Laboratory, Liverpool L3 5DA, UK. (sveta@pol.ac.uk)

J. C. Moore, College of Global Change and Earth System Science, Beijing Normal University, 19 Xinjiekou Wai St., Beijing, 100875, China. 